\title{
Direct and Indirect Measures of Sexual Maturity Preferences Differentiate Subtypes of Child Sexual Abusers
}

\author{
Alexander F. Schmidt \\ University of Bonn \\ Kim Gykiere and Kris Vanhoeck \\ ITER Outpatient Treatment Center Brussels \\ Ruth E. Mann \\ National Offender Management Service, England and Wales \\ Rainer Banse \\ University of Bonn
}

Please cite as: Schmidt, A. F., Gykiere, K., Vanhoeck, K., Mann, R. E., \& Banse, R. (in press). Direct and indirect measures of sexual maturity preferences differentiate subtypes of child sexual abusers. Sexual Abuse: A Journal of Research and Treatment.

Author Note

Alexander F. Schmidt, Social and Legal Psychology, Department of Psychology, University of Bonn, Germany; Kim Gykiere, ITER Outpatient Treatment Centre, Brussels, Belgium; Kris Vanhoeck, ITER Outpatient Treatment Centre, Brussels, Belgium; Ruth E. Mann, Commissioning Strategies Group, National Offender Management Service, London, England; Rainer Banse, Social and Legal Psychology, Department of Psychology, University of Bonn, Germany.

The authors gratefully acknowledge the helpful comments of Kelly M. Babchishin on earlier versions of this manuscript.

Correspondence concerning this article should be adressed to Alexander F. Schmidt, Institute for Psychology, Dep. Social \& Legal Psychology, University of Bonn, Kaiser-Karl-Ring 9, 53111 Bonn, Germany. Email: afschmidt@uni-bonn.de. 


\begin{abstract}
To aid risk assessment, management, and treatment planning it is essential to assess child sexual abusers' deviant sexual interests (DSI) and preferences (DSP) for sex with children. However, measurement of DSI/DSP is fraught with psychometric problems. In consequence, research interest has shifted to latency-based indirect measures as a measurement approach to complement selfreport and physiological assessment. Utilizing the Explicit and Implicit Sexual Interest Profile (EISIP) a multimethod approach consisting of self-report, viewing time, and Implicit Association Test (IAT) DSI/DSP measures - we replicated phallometric DSI/DSP differences between child sexual abuser subgroups in a sample of intrafamilial, extrafamilial, and child pornography offenders. DSI/DSP was associated with recidivism risk, offense-behavioral measures of pedophilic interest, and sexual fantasizing. It also negatively correlated with antisociality. Distinguishing between child sexual abuser subtypes and being related to recidivism risk, the EISIP is a useful tool for sexual offender assessments.
\end{abstract}

Keywords: assessment, deviant sexual interest, indirect measures, antisociality, sexual fantasy 
To aid risk assessment, management, and treatment planning it is of great value to gain insight into sexual offenders' deviant sexual interests (DSI) and preferences (DSP) ${ }^{1}$. Over the last fifteen years, meta-analyses including increasingly large numbers of studies have consistently shown that DSI/DSP (e.g., for sex with children) are among the strongest risk factors for sexual recidivism with effect sizes around $d=.30$ (Hanson \& Bussière, 1998; Hanson \& Morton-Bourgon, 2005; Mann, Hanson, \& Thornton, 2010). In line with this, recent etiological sex offending models focus, among numerous other clinical problems such as emotional dysregulation, social difficulties, cognitive distortions, or antisociality, on DSI as a causal or maintaining factor in the (re)offending process (e.g., Abel et al., 1987; Ward \& Beech, 2006; Ward \& Siegert, 2002). However, the relationship between DSI/DSP and sexual offending against children is equivocal as it is estimated that only about $25 \%$ to $50 \%$ of all such sexual offenders exhibit DSP for children (Schmidt, Mokros, \& Banse, 2012; Seto, 2008). A further complication is that the assessment of DSI is still fraught with psychometric problems (e.g., Kalmus \& Beech, 2005). As a consequence, research has recently sparked interest in latency-based indirect measures as a promising measurement approach to complement established self-report and physiological assessment protocols (e.g., Snowden, Craig, \& Gray, 2011; Thornton \& Laws, 2009a). Utilizing validated direct and indirect latency-based assessment methods - the Explicit and Implicit Sexual Interest Profile (Banse, Schmidt, \& Clarbour, 2010) - the central aim of this paper was to replicate DSI/DSP differences between specific child sexual abuser subgroups that have been established using phallometric assessment protocols.

Because of the unclear relationship between sexual offending and DSI, sexual offender assessors or therapists often need to decide whether a specific offender has an exclusive pedophilic preference, or is also to some degree, or even primarily, interested in adult sexual partners. This

\footnotetext{
${ }^{1}$ Throughout this article the term deviant sexual interest is used to denote sexual interest in prepubescent children as indicated by corresponding fantasies or behavior.Thereby, sexual interest refers to absolute levels of sexual interest in a specific target category irrespective of sexual interest in other possible categories, whereas deviant sexual preferences refer to relative sexual preferences for one target category over another target category (i.e., prepubescent over postpubescent persons).
} 


\section{SUBTYPES OF CHILD SEXUAL ABUSERS}

question holds true regardless of the chosen theoretical frame of reference, e.g., the Risk-NeedResponsivity perspective (Andrews, Bonta \& Hoge, 1990; Andrews \& Bonta, 2010) or the Good Lives Model (Ward \& Stewart, 2003; Ward, Mann, \& Gannon, 2007). Many of those convicted for sexual offending are reluctant to discuss DSI, probably for fear of reprisal, disapproval, or disadvantage. There are consequently numerous cases of impasse, where an offender refuses (or is afraid) to acknowledge any DSI but where the offending behavior raises concerns. Such offenders frequently get marooned within correctional systems, unable to satisfy the authorities that their risk has been correctly identified and addressed. A thorough assessment of the structure of deviant as well as socially accepted sexual interests is essential when tailoring individualised treatment and risk management plans.

\section{Subtypes of Child Sexual Abusers}

Given that not every child sexual abuser is pedophilic and not every individual with a diagnosis of pedophilia commits sexual offences against children (Seto, 2008), it is concluded that child sexual abuse is a heterogenic criminal - as well as psychological - phenomenon, with child sexual abusers consisting of differing subtypes. Research on this topic has so far focused on a) psychological and b) criminal-behavioral classification schemes in an effort to increase prognostic validity.

Psychological classification of child sexual abusers is based on hypothesized underlying etiological and maintaining risk factors including DSI/DSP. For example, fixated and regressed child sexual abusers have been differentiated (Groth \& Birnbaum, 1978). Alternatively, pedophilic, hebephilic, and teleophilic perpetrators are distinguished according to their primary sexual interest categories (Blanchard \& Barbaree, 2005). More fine-grained distinctions focus on etiological factors such as social incompetence, emotional dysregulation, empathy deficits, attachment problems, early maltreatment, and sexual abuse experiences. Seto (2008) integrated these factors into a developmental theory of persistent sexual offending against children, which distinguishes between 


\section{SUBTYPES OF CHILD SEXUAL ABUSERS}

antisociality and pedophilic preferences as the two main risk factors for child sexual offending that correspond with the major risk predictors for sexual recidivism in general (Mann, Hanson, \& Thornton, 2010). In this theory, DSI/DSP represent a specific subcategory of general paraphilic interests.

Criminal-behavioral classification schemes of child sexual abusers focus on behavioral manifestations exhibited in the offenses such as contact (involvement in actual sexual acts with children) vs. non-contact (e.g., child pornography use) offenders. Another distinction is based on victim characteristics such as relatedness (extrafamilial vs. intrafamilial victims), victim sex (e.g., boyor girl-only vs. offenders with mixed victims) or age, and number of victims (one time vs. repeat offenders). Empirically, recidivism risk is associated with repeated sexual abuse of male and unrelated children (Hanson \& Bussière, 1998). In terms of DSI, sexual offenders against children with unrelated male or younger victims exhibit higher phallometric DSP than subtypes with older or girlonly victims (Seto, Harris, Rice, \& Barbaree, 2004; Seto \& Lalumière, 2001). The only published study of DSI in child pornography offenders found stronger phallometric DSP for children than in contact child sexual abusers (Seto, Cantor, \& Blanchard, 2006). Intrafamilial offenders have been found to have less phallometric DSP than extrafamilial offenders (e.g., Seto, Lalumière, \& Kuban, 1999; Blanchard et al., 2006) as well as having lower levels of psychopathy (Rice \& Harris, 2002), thus exhibiting lower recidivism risk levels (Hanson \& Bussière, 1998).

\section{Assessing (Deviant) Sexual Interest}

Despite the empirically established importance of DSI to the process of (re)offending, its actual assessment suffers from substantial difficulties. This is mainly due to the questionable diagnostic validity of assessments based only on legally relevant offense behavior and/or clinical diagnoses such as pedophilia (Marshall, 2007), which imply a direct relationship between criminal behavior and psychological constructs. Furthermore, the psychometric properties of the most 


\section{SUBTYPES OF CHILD SEXUAL ABUSERS}

commonly applied measures are problematic (Kalmus \& Beech, 2005). Direct assessment procedures based on self-report suffer from their inherent transparency - probably less due to trait social desirability (Mathie \& Wakeling, 2011; Tan \& Grace, 2008) than to the legal implications of assessment in forensic contexts, and anxiety about socially ostracizing reactions of important others that are incompatible with offenders' personal aims (Maruna \& Mann, 2006). Penile plethysmography (PPG) is an established - however still rather transparent - indirect measurement approach that is well validated (Seto, 2008), but expensive and labor intensive as a method in everyday routine practice. In addition, it has been criticized for its inherent methodological shortcomings (e.g., Kalmus \& Beech, 2005; Laws, 2003; Marshall \& Fernandez, 2000).

To overcome these problems, research interest over the last years has shifted onto the development of response latency-based indirect DSI/DSP measures (e.g., Schmidt, Banse, \& Imhoff, in press; Snowden, Craig, \& Gray, 2011; Thornton \& Laws, 2009a) that capitalize on individual differences in information processing. Latency-based indirect measures are supposed to be less susceptible to deliberate manipulation because tested individuals are usually unaware of the underlying measurement rationales. Furthermore, the expression of the behavior being measured is less deliberately controllable (although people might be still aware that sexual interest is going to be assessed). Nevertheless, latency-based indirect measures have their limitations, too. As the exact underlying processes of most of these measures are yet not fully understood (De Houwer, TeigeMocigemba, Spruyt, \& Moors, 2009; Imhoff et al., 2010; Imhoff, Schmidt, Weiß, Young, \& Banse, 2012; Ó Ciardha, 2011; Schmidt, et al., in press) we prefer to focus on the nature of the dependent variable (i.e., response-latencies) to label these measurement paradigms rather than implying an established understanding of the underlying processes (as implied by the term attention basedmeasures; Gress \& Laws, 2009). Additionally, the outcomes of latency-based measures are potentially influenced by contextual (e.g., stimulus, instruction, and experimenter effects) and

personal (e.g., general executive functioning) moderators (De Houwer et al., 2009; Gawronski, 


\section{SUBTYPES OF CHILD SEXUAL ABUSERS}

Deutsch, \& Banse, 2011). Thus, it is questionable to draw strong inferences about psychological trait attributes from any single indirect measure (including PPG), especially at the single-case level (as of course is true for direct measures as well).

A solution to the problem of diagnostic inference lies in the combination of several conceptually different direct and indirect measures in test batteries. When several measures are used that tap into different processes or representations of DSI/DSP, measurement error is reduced due to the diagnostic convergence principle (i.e., diagnostic conclusions can be drawn with greater confidence if they are based on the aggregation of valid but conceptually different measures producing convergent results; Epstein, 1983). The Explicit and Implicit Sexual Interest Profile (EISIP; Banse et al., 2010) is a multimethod approach based on this rationale that combines a self-report questionnaire with viewing time measures (Imhoff et al., 2010) and Implicit Association Tests (IATs; Greenwald, McGhee, \& Schwartz, 1998) to assess sexual gender and maturity preferences. The EISIP has been shown to be a reliable and valid test battery that discriminates well between child sexual offenders and differing non-sexual and non-offender controls (Banse et al., 2010) and represents an effective way of assessing DSI/DSP.

\section{Current Study}

Indirect latency-based measures provide a new and promising data source in addition to classic behavioral, physiological and self-report measures of DSI (Schmidt, et al., in press). Empirical evidence of convergent validity in forensic contexts has been reported for varying combinations with direct self-report, behavioral offense data, additional indirect latency-based, and/or PPG-measures (e.g., Abel, Jordan, Hand, Holland, \& Phipps, 2001; Banse et al., 2010; Harris, Rice, Quincy, \& Chaplin, 1996; Letourneau, 2002; Stinson \& Becker, 2008). However, as the underlying processes of latencybased measures are not well understood, replications of established clinical findings on differential child sexual offender subgroups with these new measurement approaches are mandatory. Each new 


\section{SUBTYPES OF CHILD SEXUAL ABUSERS}

study of this nature represents an advancing step towards the clinical applicability and implementation of indirect measures as effective assessment tools for DSI/DSP (Thornton \& Laws, 2009b).

To contribute to this growing literature, the central aims of this study were a) to examine the associations of response-latency measures with risk assessment measures and offending behavior; and b) to replicate findings from PPG studies on DSI/DSP differences between child molester subgroups using latency-based indirect measures. In accordance with the literature (Seto et al., 1999; Blanchard et al., 2006), we expected intrafamilial abusers to exhibit less DSP than extrafamilial child molesters and child pornography users. We also hypothesized positive correlations of DSI/DSP with reoffending risk and behavioral sexual deviance markers. We chose to compare these specific child sexual offender subgroups because of the clear separation of comparison groups based on offencebehavioral criteria instead of inferences on underlying offence motivations and etiological factors.

Additionally, we wanted to explore the relationship of antisociality with DSI in child sexual offenders against children. According to the developmental theory of persistent child sexual offending (Seto, 2008; Seto et al., 2004), these factors would be expected to be independent from each other. However, there have been reports indicative of negative associations between both constructs: Psychopaths (vs. non-psychopaths) were more likely to victimize older girls and offended less often against younger children in general and boys specifically (Harris, Rice, Hilton, Lalumière, \& Quinsey, 2007). On the other hand, utilizing a PPG index of deviant sexual arousal to children Firestone, Bradford, Greenberg, and Serran (2000) reported a positive correlation between psychopathy and DSP in extrafamilial child molesters (as well as a non-significant negative association with intrafamilial offending). In a methodologically weaker study, due to small sample sizes and a combined PPG DSP index of deviant sexual arousal to children and sexual violence, Serin, Malcolm, Khanna, and Barbaree (1994) found differential (non-significant) correlations with psychopathy scores for intrafamilial $(r=-.18)$ vs. extrafamilial $(r=.42)$ child molesters . In summary, 


\section{SUBTYPES OF CHILD SEXUAL ABUSERS}

the findings on the relationship between antisociality and DSI/DSP are mixed and no clear hypothesis can be derived from the literature.

Finally, Banse et al. (2010) reported that child sexual offenders (vs. offender and non-offender controls) generally exhibited higher levels of sexual interest across all EISIP-measures, which was interpreted as a possible indication of sexual preoccupation. To further explore this hypothesis of generally increased sexual interest among child sexual abusers, we were interested in the relationship between self-reported sexual fantasizing and DSI. We expected the overall extent of sexual fantasies across all sexual target categories (as a proxy for sexual preoccupation) to be associated with both DSI and reoffending risk.

\section{Method}

\section{Participants}

The sample consisted of 72 sexual offenders against children of Caucasian ethnic origin (to exclude possible interaction effects of the ethnic origin of child sexual abusers and target stimuli) from a Belgian outpatient treatment institution that is part of a broader community health center funded by the Ministry of Health and Welfare. All victims were below the age of 16 as required by the Belgian penal code. Admission was either court-ordered ( $82 \%$ of the sample) or voluntary without the involvement of the justice system. Because of this, criminal records necessary for Static99R (Helmus, Thornton, Hanson, \& Babchishin, 2012) evaluations were available only for the subgroup of 59 child sexual abusers under mandatory treatment. The present sample represented the whole population of Flemish-speaking non-incarcerated child sexual abusers facing court-ordered outpatient treatment in the Brussels catchment area over the time period from 2008 to 2011. The measurement battery used in this study was part of the routine intake assessment.

The sample was composed of three subgroups: (1) intrafamilial abusers ( $n=19$ or $26.4 \%$; 17 with girl-victims only), who exclusively molested related victims according to the definition of the 


\section{SUBTYPES OF CHILD SEXUAL ABUSERS}

Screening Scale for Pedophilic Interests item (SSPI; Seto \& Lalumière, 2001; see below), (2) extrafamilial abusers ( $n=35$ or 48.6\%; 19 with girl-victims exclusively), who had at least one unrelated victim; and (3) child pornography offenders ( $n=18$ or $25 \%$ ) who were not convicted of any contact offences against children. Age ranged between 18 and $64(M=40.1, S D=11.3)$ with no significant group differences between the child sexual abuser subgroups (Table 1). The majority of cases fell into moderate risk categories. However, substantial 9\% (Static-99R categories) and 26\% (SVR-20 ratings) of the sample were classified as high-risk offenders (Table 1).

\section{Measures}

Explicit and Implicit Sexual Interest Profile (EISIP). The EISIP (Banse et al., 2010) is a multimethod test battery consisting of direct and indirect measures of sexual maturity preferences. In this study a Flemish language version was used. The order of measurement tasks is viewing time, IATs, followed by a self-report measure. All trials and items are presented in a fixed quasirandomized order to maximize between-person effects.

The direct measure used in the EISIP is the 40-item Explicit Sexual Interest Questionnaire (ESIQ; Banse et al., 2010) featuring the two subscales sexual behavior (e.g., "I have sexually caressed a man/woman/boy/girl.") and sexual fantasies (e.g., "I have daydreamed of having sex with a man/woman/boy/girl"). Each scale contains five items referring to each of four sexual interest target categories (men, women, prepubescent boys, prepubescent girls). Items are responded to in a dichotomous yes/no format. Corresponding scale frequency scores are calculated from the mean amount of "yes" responses (higher scores reflect higher frequencies of sexual behaviors and fantasies). Additionally, the sexual fantasy subscales were aggregated into a mean general sexual fantasizing score across target categories. Higher levels on all ESIQ-scores correspond to higher frequencies of self-reported sexual fantasies or behaviors. 


\section{SUBTYPES OF CHILD SEXUAL ABUSERS}

The first indirect measure in the EISIP is a viewing time (VT) measure of sexual interest in female and male targets of varying sexual maturity stages (eight stimuli for each of the five stages of sexual maturity according to Tanner (1978); Tanner stages 1 to 3 depicting prepubescent, Tanner 4 (adolescent) and Tanner 5 (adult) postpubescent stimuli). Participants are asked to rate the sexual attractiveness of the target stimuli on a five-point Likert-scale ranging from 1 ("sexually unexciting") to 5 ("sexually very exciting") without time constraints (Imhoff et al., 2010). Eighty stimulus pictures - all of Caucasian individuals in bathing clothes from the Not-Real-People (NRP) picture sets A and B (Pacific Psychological Assessment Corporation, 2004) - are presented on the PC monitor until the participant responds, while VT is unobtrusively recorded (higher levels reflect longer VTs). Individual response latencies were truncated at $10,000 \mathrm{~ms}$ and averaged across the eight stimuli belonging to each target category. No suspiciously short VT was observed (all single latencies $\geq 420 \mathrm{~ms}$ ).

Additionally, the EISIP contains three different Implicit Association Tests (IATs) with the target categories man vs. woman, girl vs. woman, and boy vs. man, and the attribute categories sexually exciting vs. unexciting. These target categories were conceptualized according to Ahlers et al.'s (2006) suggestion to differentiate between sexual orientation (hetero- vs. homosexual) and sexual maturity preference (children vs. adults) in the classification of sexual disorders. Sexual orientation is measured with the Men-Women IAT and maturity preference with the Girls-Women and the Boys-Men IATs to distinguish gender-specific DSP. Each IAT consists of five blocks following standard procedures as described in Greenwald, McGhee, and Schwartz (1998) with an increased number of trials. All blocks were presented in a fixed order as described in the following. The stimulus pictures are the same as in the VT task. The first block of 40 trials comprises a categorisation task of ten words that have to be classified as sexually exciting (erotic, exciting, lustful, sensual, orgasm) or unexciting (dull, bland, indifferent, unexciting, boring). In the second 40-trial block, ten NRP pictures have to be assigned to the categories man vs. woman (girl vs. woman, boy vs. man, respectively) by correspondingly pressing the left or right response key. In the third block, both tasks 


\section{SUBTYPES OF CHILD SEXUAL ABUSERS}

are mixed in alternating order. Four practice trials precede 80 test trials. The left response key has to be pressed for items belonging to the categories man or sexually unexciting, the right response key for items for woman or sexually exciting. The fourth block of 40 trials is similar to the second, but the key assignment is reversed. In the fifth and final block of four practice plus 80 test trials, both tasks are again combined. In this final block the left response key has to be pressed for items relating to the categories man or sexually exciting, and the right response key for items relating to woman or sexually unexciting. For the Boys-Men and Girls-Women IATs the target categories are accordingly changed. Incorrect responses are indicated by an error message to the participant throughout all blocks without requiring a further correct response.

The IATs are scored by calculating the difference between the mean response latencies of the critical third and fifth block, divided by the pooled standard deviation of response latencies (Greenwald, Nosek, \& Banaji, 2003). This individual effect size measure reflects relative sexual preferences for one target category over the other and controls for individual differences in executive functioning abilities (De Houwer et al., 2009). For the Girls-Women and Boys-Men IATs, higher scores represent preference for girls over women and boys over men, respectively. In the Men-Women IAT, higher scores represent preference for men over women. Only correct trials were used for the analyses. Furthermore, as a proxy for general executive functioning a processing speed measure was calculated from the combined mean latencies in the simple word and picture categorisation tasks of the Men-Women IAT (blocks 1 and 2) as a control variable.

Aggregation across the raw EISIP measures resulted in three higher-order relative DSP difference scores. As aggregation across target gender categories could possibly obscure genderspecific DSP we refrained from averaging across male and female stimuli. Instead, we chose to use deviance indexes based on maximum means of gender-specific categories - a scoring technique commonly used in PPG assessments (Harris, Rice, Quinsey, Chaplin, \& Earls, 1992). For the ESIQ and VT Deviance Indexes this was done by subtracting maximum mean sexual interest in postpubescent 


\section{SUBTYPES OF CHILD SEXUAL ABUSERS}

females or males from maximum mean interest levels for prepubescent girls or boys. As the MenBoys and the Girls-Women IATs inherently reflect difference scores of child over adult categories the maximum gender-specific IAT was used as the corresponding DSP score (IAT Deviance Index). For all three Deviance Indexes higher scores reflect relatively more DSP. DSP scores were finally aggregated into a general sexual maturity preference score by averaging over $z$-values of the respective ESIQ, VT, and IAT Deviance Indexes. This highest-level aggregate score reflects the maximum DSP level across all EISIP-measures with higher scores indicating more DSP for children over adults.

Screening Scale for Pedophilic Interest (SSPI). The SSPI (Seto \& Lalumière, 2001) is an offense-behavioral four-item index based on offenders' sexual victim characteristics (any male victims, more than one victim, any victims $<11$ years of age, any extrafamilial victims). An extrafamilial victim is defined as "a child who was not the offender's son or daughter, stepson or stepdaughter, or a member of his extended family" (Seto \& Lalumière, 2001, p. 19). Every item that is present is scored 1 (with the exception of any male victim scored with 2) so scores range from 0 to 5 . The SSPI has been shown to predict phallometrically assessed sexual arousal to children (Seto \& Lalumière, 2001) and serious violent or sexual reoffending in adult male child sexual offenders (Seto et al., 2004).

Static-99R. The ten-item Static-99R (Helmus et al., 2012) is a modified version of the Static99 (Hanson \& Thornton, 2000), the most widely used actuarial sex offender risk assessment instrument. It is based on empirically validated risk factors for sexual recidivism. The modified Static99R with revised age-weights has been shown to better estimate sexual as well as violent recidivism rates in the validation sample than its former versions (Helmus et al., 2012). Although Static-99R coding rules exclude internet sexual offenders, we chose to use it for this offender subgroup as well. Risk markers for offline offenders such as identified in the Static-99R will be likely to be helpful for risk assessments with online sexual offenders because they tap a common pool of risk factors and perform similarly across different types of sexual offenders (Seto, Hanson, \& Babchishin, 2011). 


\section{SUBTYPES OF CHILD SEXUAL ABUSERS}

Sexual Violence Risk - 20 (SVR-20). The SVR-20 (Boer, Hart, Kropp, \& Webster, 1997) is a 20-item structured clinical judgement instrument to assess the risk for sexual violence. It comprises the three main categories psychosocial adjustment, history of sexual offences, and future plans. Sum scores (possible range from 0-40) as well as clinically judged risk categories have been shown to predict sexual, violent, and general recidivism (e.g., de Vogel, de Ruiter, van Beek, \& Mead, 2004). In addition to sum scores and clinical judgements, we calculated a mean Antisociality Index (possible range from -2 to +2 ) consisting of the mean of SVR-20 items that are theoretically and empirically related to antisocial behavior (i.e., psychopathy, substance abuse, employment problems, non-sexual prior offending, non-violent prior offending). Higher index values point to more antisociality risk indicators.

\section{Results}

Control variables. Risk levels were not equally distributed across child sexual offender groups for the Static-99R scores (Table 1 ) and as a trend for the SVR-20 category ratings $\left(\chi^{2}(4)=8.65\right.$, $p=.070)$. Contact child sexual abusers showed higher risk categories than child pornography offenders. However, at least for the Static-99R and the SSPI these differences were not surprising because extrafamilial victims (Static-99R, SSPI) are considered a risk factor in both scales and child pornographic depictions do not count for the Static-99R victim items according to coding rules. The (marginally significant) difference on the SVR-20 clinical judgements might be explained by the fact that exclusive internet sexual offenders are usually regarded as low risk (Seto et al., 2011). Contrary to Static-99R risk scores and SSPI levels, SVR-20 scores did not differ between groups. This might be due to the fact that the SVR-20 risk score depends on a broader conceptualization of recidivism risk including some at least partially dynamic risk factors as opposed to the exclusively static indicators in the Static-99R (and the SSPI) that were partially confounded with child sexual abuser subgroup criteria. 


\section{(insert Table 1)}

As all indirect measures relied on response latencies, it was of primary interest to rule out individual differences in general executive functioning as a possible confound in this heterogenic sample of sexual offenders against children. One intrafamilial child sexual abuser had a value $>3 S D$ s on the cognitive processing speed measure and was thus excluded from all processing speed analyses. Child sexual abuser subgroups showed no differences in processing speed (Table 1). As to be expected, processing speed, assessed by mean correct person (men vs. women) and word classification (sexually exciting vs. unexciting) latencies in the first two IAT-blocks, was correlated with age $(r=.40 ; p=.001)$. However, it was unrelated to all EISIP sexual interest measures, except for VT Men. Controlling for shared variance with processing speed, age was unrelated to any sexual interest indicator of the EISIP (Table 2).

(insert Table 2)

Reliabilities. Internal consistencies (Table 2) of all EISIP raw measures were $\alpha>.80$, except for the Boys-Men IAT ( $\alpha=.61)$, which can be regarded as good and comparable to the coefficients reported by Banse et al. (2010).

\section{Relationship of Deviant Sexual Interest with Offense Behavior, Antisociality, and Risk Markers}

Table 2 indicates that most EISIP measures correlated, with significant small to medium effect sizes, with offense behavior indicating pedophilic interest (SSPI). That is, SSPI scores showed positive associations with DSI in girls, boys (ESIQ, VT, IAT, except for VT girls and the Boys-Men IAT), as well as DSP for children compared to adults (ESIQ, VT, IATs, and EISIP aggregated Deviance Indexes). SSPI scores were negatively correlated with sexual interest or preferences for women (ESIQ, VT). Homosexual orientation markers reflected similar associations that were indicated by positive correlations with the ESIQ and VT Men and Boys subscales. 


\section{SUBTYPES OF CHILD SEXUAL ABUSERS}

This pattern reversed in child sexual abusers exclusively victimising girls (Table 2). Girls-only molesters in this sample ( $n=36 ; 17$ intrafamilial offenders) appeared to be primarily non-deviant with positive correlations for markers of sexual interest in women (ESIQ and VT) and negative correlations for sexual interest indicators in male and female children (ESIQ, VT, IATs), as well as negative associations with all Deviance Indexes for children over adults. Only DSI in girls (ESIQ and VT) and DSP for girls over women (IAT) were uncorrelated with girls-only abuse. These findings indicate that girlsonly abusers were mainly heterosexual and non-deviant. Antisocial child sexual abusers showed positive associations with sexual interest in women (VT Women) as well as a marginally significant ( $p$ $<.08)$ positive correlation with VT for girls (Table 2), corroborating lesser DSI.

Resembling the associations with the SSPI, somewhat smaller effect sizes emerged for the actuarial Static-99R risk scores (Table 2). Viewing time and IAT Deviance Indexes, IAT Girls-Women and homosexual preference indicators (ESIQ Men, Men-Women IAT) were associated with higher Static-99R scores. Simple DSI indicators such as ESIQ Girls, VT Girls, and VT Boys, as well as VT Men, did not correlate with Static99-R recidivism risk. However, IAT DSP of boys over men was associated with Static-99R scores indicating that also the more specific DSP of male children over male adults and not only adult homosexual orientation was correlated with reoffending risk. Neither SVR-20 scores nor structured clinical judgments of reoffending risk (SVR-20 category ratings) were related to any EISIP measure (Table 2).

On the highest aggregation level across all EISIP DSP indexes (Table 2, last row), on which measures should benefit the most from the aggregation principle (i.e., show the least measurement error), the correlation pattern was more pronounced (medium effect sizes). As expected, aggregated EISIP DSP showed robust positive associations with offense-behavioral markers of DSI (SSPI) and recidivism risk (Static-99R), but no association with the SVR-20 measures. Also, the aggregated EISIP Deviance Index was negatively correlated with exclusive abuse of female children. 


\section{(insert Table 3)}

The Antisociality Index in this study was negatively related to indicators of DSI as shown by the negative correlations with child pornography offending (that involves actively seeking out sexually deviant stimulus material) and the SSPI (Table 3) as well as the positive association with VT women (Table 2). Associations with the SVR-20 score and clinical judgements were trivial as the Antisociality Index was derived from an item subset of the SVR-20. Additionally - as hypothesized general sexual fantasizing was positively correlated with the aggregated EISIP Deviance Index (Table 2), the SSPI, and the Static-99R (all Table 3), tapping well into clinically relevant DSI/DSP and recidivism risk measures. Again, no associations with SVR-20 risk estimations were demonstrated.

\section{(insert Table 4)}

Group differences between child sexual abuser subtypes. As hypothesized, intrafamilial offenders exhibited the lowest amount of DSP compared to extrafamilial abusers and child pornography users (Table 4). Intrafamilial child sexual abusers were the most antisocial subtype in this sample, with the other two groups showing lesser levels of this disposition. Corresponding with the correlational pattern described above, intrafamilial abusers significantly more often victimised girls exclusively than extrafamilial offenders $\left(\chi^{2}(1)=6.86, p=.014\right)$. In post-hoc tests extrafamilial child molesters and internet pornography offenders did not differ from each other in terms of DSP and antisociality levels (Table 4).

\section{Deviant Sexual Interest and Sexual Fantasizing}

As hypothesized, self-reported general sexual fantasizing was highest in the most deviant extrafamilial group (Table 4). General fantasizing levels were statistically equal for the child pornography and intrafamilial groups. However, child pornography offenders reported a lower amount of sexual fantasies than the extrafamilial offenders. The relationship of the mean sexual fantasy frequencies with DSI (Table 2) was characterized by a pattern of negative correlations with VT 


\section{SUBTYPES OF CHILD SEXUAL ABUSERS}

Women and positive associations with VT Girls and DSP (VT Deviance Index, as well as the GirlsWomen, Boys-Men IATs, and the IAT Deviance Index). Additionally, general sexual fantasizing was positively associated with higher amounts of self-reported sexual behavior with boys, girls, men, and the self-reported Deviance Index (Table 2).

Similar to the aggregated EISIP Deviance Index, general fantasizing results could have emerged due to differential underlying patterns that were obscured by higher-level cross-gender aggregation. To further examine this possibility, we inspected the distribution of fantasies over sexual target categories (Figure 1) and calculated a correpsonding maximum deviant fantasy index corresponding to the other maximum deviance indexes used in this study. This difference measure is also indicative of the specificity of sexual maturity preferences (i.e., the higher its absolute value, the more specific the corresponding preference). Groups differed significantly on their sexual fantasy specificity (Table 4). Intrafamilial offenders reported the most specific and least deviant sexual fantasies that significantly differed from child pornography offenders as the least specific but most deviant group, whereas extrafamilial offenders did not differ from the other groups.

\section{(insert Figure 1)}

\section{Discussion}

Deviant sexual interest, offending behavior and reoffending risk. Clinically important group differences between intra- and extrafamilial child sexual abusers and child pornography users that have been demonstrated in phallometric studies were replicated in this study. Intrafamilial offenders exhibited lower DSP than extrafamilial offenders (congruent with Seto et al., 1999; Blanchard et al., 2006). We also replicated the positive associations between the offending behavior indicative of pedophilic interest (SSPI) and EISIP DSI reported in Banse et al. (2010). Additionally, we found that the EISIP converged with actuarial risk assessment (Static-99R), further supporting the clinical usefulness of indirect measures of DSI/DSP such as VT and IATs in forensic contexts. To the 


\section{SUBTYPES OF CHILD SEXUAL ABUSERS}

best of our knowledge, so far only Nunes, Firestone, and Baldwin (2007) have shown similar associations between a DSP IAT variant and risk measures for child sexual abusers. For VT this is the first report of convergence with an actuarial risk assessment instrument. Unexpectedly, we did not find any associations with recidivism risk as assessed by the SVR-20. Whether this is due to the different conceptualization of recidivism risk in the Static-99R (exclusively static predictors with a strong emphasis on sexual deviance) and SVR-20 (dynamic risk-factors included, less focused on sexual deviance) remains an open question for future research. However, for a subset of SVR-20 items indicating antisociality we found negative associations with DSI markers that are discussed further below.

Executive functioning as potential confound of IATs and VT. As the underlying processes of response latency-based measures are yet not well understood (Imhoff et al., 2010; Imhoff et al., 2012; Schmidt, et al., in press; Snowden, Craig, \& Gray, 2011; Thornton \& Laws, 2009a) the finding that the VT and IAT measures used in this study were free from general processing speed biases is another important addition to the literature. This further supports the validity of indirect latencybased meausres as indicators of DSP/DSI. It is a first indication that general executive functioning as well as age (if corrected for processing speed) do not impair the results from these assessment approaches and supports the comparability of results from populations that empirically differ in their general cognitive abilities (e.g., non-offending control samples, sexological research with convenience samples), thus strengthening the clinical applicability of latency-based measures.

\section{Deviant Sexual Interest and Antisociality}

We found negative correlations between the Antisociality Index and child pornography offending and pedophilic offending behavior (SSPI). Antisociality was further positively associated with indirectly assessed sexual interest in Women (VT). Marginally significant positive correlations were found with VT for girls (girls-only child sexual abusers primarily comprised less deviant 


\section{SUBTYPES OF CHILD SEXUAL ABUSERS}

intrafamilial offenders in this sample). This indicates that in the current study antisociality was negatively associated with DSI, in contrast to empirical findings by Seto et al. (2004) and theoretical postulations from the developmental theory of persistent child sexual offending (Seto, 2008). For incest offenders, earlier research has found similarly small negative effect sizes between psychopathy and a PPG index of DSP for children (Firestone et al., 2000) or a combined PPG DSP index for children and violence (Serin et al., 1994). These findings may indicate that antisocial offenders are more likely to opportunistically victimize more sexually developed girls and less likely to victimize younger children or boys (Harris et al., 2007). The lesser DSI/DSP levels of the intrafamilial child sexual abusers also lend further support to opportunism, which can be regarded as a personality trait related to antisociality/psychopathy and which seems to function as an important etiological factor of intrafamilial child sexual abuse as discussed by Rice and Harris (2002).

However, the finding of increased levels of antisociality for intrafamilial abusers in this study contrasts with the decreased psychopathy levels previously reported for this subgroup of child sexual abusers (Rice \& Harris, 2002). It is possible that this difference is attributable to the differing operationalisations of antisociality/psychopathy, different DSP/DSI measures (PPG vs. latency-based assessments) used in the studies, or varying sample characteristics (e.g., the definition of intrafamilial/incest abuse). Thus, this finding is in need of replication, especially using a more established and hence comparable measure of antisociality/psychopathy.

\section{Deviant Sexual Interest and Homosexual Orientation}

Another debated question concerns the relationship of male homosexual orientation (i.e., a sexual preference for adult male over adult female stimuli) with DSP for children. Similar to Banse et al. (2010) we found in this study that homosexual orientation was associated with DSI. This association might be attributable to a sexual orientation confound in the sample. As in the former study where gay control participants were lacking, in this sample homosexual orientation (as 


\section{SUBTYPES OF CHILD SEXUAL ABUSERS}

indicated by self-reporting any sexual fantasy involving male adults in the ESIQ) was confounded with extrafamilial child sexual abuse: Eleven out of 13 gay child abusers ( $18 \%$ of the sample) had molested unrelated victims $\left(\chi^{2}(2)=8.23, p=.015\right)$. Hence, the correlations between gay interest, as indicated by ESIQ Men and VT Men, with behavioral indicators of pedophilic preferences (SSPI) in this study were driven by extrafamilial abusers. Additionally, self-reported sexual interest in men (ESIQ Men) and a sexual preference for men over women (Men-Women IAT) were also associated with Static99R risk scores (scoring extrafamilial victims as a risk factor in their conception). The Boys-Men IAT as an indirect measure of genuine DSP may shed some light on these associations: In the present sample, DSP for boys over men was significantly related to the Static-99R and having at least one boy victim. This finding therefore indicates that preferences for boys over men at least partially have driven the association between homosexual orientation and recidivism risk. One further possible explanation might be that in this sample the extrafamilial child molesters exhibited a broader (i.e., less differentiated) pattern of sexual interest across all target categories. Preliminary support for this hypothesis can be found in the pattern of self-reported sexual fantasies showing the highest fantasizing levels for extrafamilial offenders across sexual maturity categories (Figure 1, see discussion below).

\section{Deviant Sexual Interest, Sexual Fantasizing and Sexual Preoccupations}

As hypothesized, the most sexually deviant subgroup in this sample (i.e., extrafamilial abusers) reported the highest frequencies of different sexual fantasies across all adult and child sexual target categories. Notably, intrafamilial molesters reported the most specific and least deviant sexual fantasies whereas child pornography users reported the least specific but most deviant sexual fantasies in favor of children compared to adults. These results support the fact that different paraphilic behaviors tend to co-occur and pedophiles are more likely than men selected from the general population to engage in other paraphilic behaviors (Seto, 2008), thus increasing the odds of experiencing a broader range of deviant and more intense sexual fantasies. These greater self- 


\section{SUBTYPES OF CHILD SEXUAL ABUSERS}

reported fantasy levels could be symptomatic of higher sex drive and/or sexual preoccupation as well as of a subtype of undifferentiated sexual interest across sexual maturity stages and/or other paraphilic domains. These constructs should be included in future research with indirect measures to further clarify the underlying processes that drive the associations between DSI and reoffending risk. Another - not necessarily mutually exclusive - explanation for the broader range of sexual fantasies of child pornography users might be that acutely sexually aroused individuals tend to get more diverse in their sexual interests (Ariely \& Loewenstein, 2006; Imhoff \& Schmidt, 2013). This disinhibitory process might explain why child pornography users while surfing for their preferred sexual content on the internet may develop less specific fantasy preferences.

In line with these accounts, it has been shown that a subgroup of child pornography users tended to cruise across diverse sexual content categories (24\%; Sullivan, 2007) and about $70 \%$ of two large samples of arrested child pornography possessors had also collected adult pornographic material (Wolak, Finkelhor, \& Mitchell, 2011). Future research should examine these individual differences in sexual fantasizing patterns more systematically. Again, the amount and variety of sexual fantasies might be indicative of sexual preoccupations and/or high sex drive, both being major risk factors for sexual dysregulation (Winters, Kalina, \& Gorzalka, 2010). Sexual self-regulation as well as individual sex drive differences are promising moderators of the equivocal relationship between DSI/DSP and sexual offending against children that are worth exploring in future studies (Hanson, 2010).

\section{Limitations}

There are some limitations to this study that have to be taken into account. The relatively small number of child sexual abusers from a single treatment facility with its specific admission criteria limits generalization across different samples (e.g., incarcerated high-risk sexual offenders). However, the results of this study confirmed hypotheses based upon empirical and clinical findings 


\section{SUBTYPES OF CHILD SEXUAL ABUSERS}

from other samples in the literature thus speaking against strong sample-specific biases. In terms of the demonstrated associations with risk assessment measures, it has to be pointed out that these are merely cross-sectional. Hence, future research should focus on prospective designs in order to be able to draw stronger conclusions about the true predictive validity of indirect measures (preferably in combination with PPG assessments to test for incremental validity).

\section{Conclusions}

In summary, using self-report and latency-based indirect measures of sexual interest, this study has shown that intrafamilial child sexual abusers are less likely to exhibit DSP than extrafamilial molesters or child pornography users; that DSI/DSP correlates with recidivism risk as assessed with the Static-99R (but not with the SVR-20) and offense behavior indicative of sexual deviance; and that higher risk offenders report more varied deviant and non-deviant sexual fantasizing. The study also indicates that antisociality is negatively associated with deviant sexual interest and may account for a separate route to sexual offending, particularly for intrafamilial offenders.

Additionally, this study provides further support for the EISIP as a reliable and valid noninvasive assessment tool of DSI/DSP. Being able to distinguish between deviant and non-deviant child sexual abusers as well as being related to recidivism risk, the EISIP can be regarded as an useful additional clinical tool for sexual offender evaluations that involve the question of an individual's specific pattern of deviant (and non-deviant) sexual maturity preferences and interests. In applied settings, where the question of possible DSI/DSP can become a key matter for evaluators (and indeed for offenders), we believe that a combination of conceptually different direct and indirect measures such as in the EISIP provides a valuable methodology to explore various specific features of sexual interest patterns. 


\section{References}

Abel, G. G., Becker, J. V., Mittelman, M., Cunningham-Rathner, J., Rouleau, J. L., \& Murphy, W. (1987). Self-reported sex crimes of nonincarcerated paraphiliacs. Journal of Interpersonal Violence, 2, 3-25. doi:10.1177/088626087002001001

Abel, G. G., Jordan, A., Hand, C. G., Holland, L., \& Phipps, A. (2001). Classification models of child molesters utilizing the Abel Assessment of Sexual Interest. Child Abuse \& Neglect, 25, 703-718. doi:10.1016/S0145-2134(01)00227-7

Ahlers, C. J., Schaefer, G. A., \& Beier, K. M. (2006). Das Spektrum der Sexualstörungen und ihre Klassifizierbarkeit in ICD-10 und DSM-IV [The spectrum of sexual disorders and their classifiability in ICD-10 and DSM-IV]. Sexuologie, 12, 120-152.

Andrews, D., \& Bonta, J. (2010). The psychology of criminal conduct ( $5^{\text {th }}$ ed.). New Providence, NJ: LexisNexis Matthew Bender.

Andrews, D. A., Bonta, J., \& Hoge, R. D. (1990). Classification for effective rehabilitation: Rediscovering psychology. Criminal Justice and Behavior, 17, 19-52. doi:10.1177/0093854890017001004

Ariely, D. \& Loewenstein, G. (2006). The heat of the moment: The effect of sexual arousal on sexual decision making. Journal of Behavioral Decision Making, 19, 87-98. doi: 10.1002/bdm.501

Banse, R., Schmidt, A. F., \& Clarbour, J. (2010). Indirect measures of sexual interest in child sex offenders: A multi-method approach. Criminal Justice and Behavior, 37, 319-335. doi:10.1177/0093854809357598

Barbaree, H. E., Seto, M. C., Langton, C. M., \& Peacock, E. J. (2001). Evaluating the predictive accuracy of six risk assessment instruments for adult sex offenders. Criminal Justice and Behavior, 28, 490-521. doi:10.1177/009385480102800406 


\section{SUBTYPES OF CHILD SEXUAL ABUSERS}

Blanchard, R., \& Barbaree, H. E. (2005). The strength of sexual arousal as a function of the age of the sex offender: comparisons among pedophiles, hebephiles, and teleiophiles. Sexual Abuse: $A$ Journal of Research and Treatment, 17, 441-456. doi:10.1177/107906320501700407

Blanchard, R., Kuban, M. E., Blak, T., Cantor, J. M., Klassen, P., \& Dickey, R. (2006). Phallometric comparison of pedophilic interest in non-admitting sexual offenders against stepdaughters, biological daughters, other biologically related girls and unrelated girls. Sexual Abuse: A Journal of Research and Treatment, 18, 1-14. doi:10.1007/s11194-006-9000-9

Boer, D. P., Hart, S. D., Kropp, P. R., \& Webster, C. D. (1997). The Manual for the Sexual Violence Risk 20. Burnaby, British Columbia: Simon Fraser University.

De Houwer, J., Teige-Mocigemba, S., Spruyt, A., \& Moors, A. (2009). Implicit measures: A normative analysis and review. Psychological Bulletin, 135, 347-368. doi:10.1037/a0014211

de Vogel, V., de Ruiter, C., van Beek, D. \& Mead, G. (2004). Predictive validity of the SVR-20 and Static-99 in a Dutch sample of treated sex offenders. Law and Human Behavior, 28, 235-251. doi:10.1023/B:LAHU.0000029137.41974.eb

Epstein, S. (1983). Aggregation and beyond: Some basic issues on the prediction of behavior. Journal of Personality, 51, 360-392. doi:10.1111/j.1467-6494.1983.tb00338.x

Firestone, P., Bradford, J. M., Greenberg, D. M., \& Serran, G. A. (2000). The relationship of deviant sexual arousal and psychopathy in incest offenders, extrafamilial child molesters, and rapists. Journal of the American Academy of Psychiatry and Law, 28, 303-308.

Gawronksi, B., Deutsch, R., \& Banse, R. (2011). Response-interference tasks as indirect measures of automatic associations. In K. C. Klauer, A. Voss, \& C. Stahl (Eds.), Cognitive methods in social psychology (pp. 78-123). New York, NY: Guilford.

Greenwald, A. G., McGhee, D. E., \& Schwartz, J. L. K. (1998). Measuring individual differences in implicit cognition: The Implicit Association Test. Journal of Personality and Social Psychology, 74, 1464-1480. doi:10.1037//0022-3514.74.6.1464 


\section{SUBTYPES OF CHILD SEXUAL ABUSERS}

Greenwald, A. G., Nosek, B. A., \& Banaji, M. R. (2003). Understanding and using the Implicit Association Test: I. An improved scoring algorithm. Journal of Personality and Social Psychology, 85, 197-216. doi:10.1037/h0087889

Gress, C. L. Z., \& Laws, R. D. (2009). Measuring sexual deviance: Attention-based measures. In A. R. Beech, L. A. Craig, \& K. D. Browne (Eds.), Assessment and treatment of sex offenders: A Handbook (pp. 109-128). New York, NY: Wiley-Blackwell.

Groth, A. N., \& Birnbaum, H. J. (1978). Adult sexual orientation and attraction to underage persons. Archives of Sexual Behavior, 7, 175-181. doi:10.1007/BF01542377

Hanson, R. K. (2010). Dimensional measurement of sexual deviance. Archives of Sexual Behavior, 39, 401-404. Doi:10.1007/s10508-009-9575-6

Hanson, R. K., \& Bussière, M. T. (1998). Predicting relapse: A meta-analysis of sex offender recidivism studies. Journal of Consulting and Clinical Psychology, 66, 348-362. doi:10.1037//0022$006 \times .66 .2 .348$

Hanson, R. K., \& Morton-Bourgon, K. E. (2005). The characteristics of persistent sexual offenders: A meta-analysis of recidivism studies. Journal of Consulting and Clinical Psychology, 73, 11541163. doi:10.1037/0022-006X.73.6.1154

Hanson, R. K., \& Thornton, D. (2000). Improving risk assessments for sex offenders: A comparison of three actuarial scales. Law and Human Behavior, 24, 119-136. doi:10.1023/A:1005482921333

Harris, G. T., Rice, M. E., Hilton, N. Z., Lalumière, M. L., \& Quinsey, V. L. (2007). Coercive and precocious sexuality as a fundamental aspect of psychopathy. Journal of Personality Disorders, 21, 1-27. doi:10.1521/pedi.2007.21.1.1

Harris, G. T., Rice, M. E., Quinsey, V. L., \& Chaplin, T. C. (1996). Viewing time as a measure of sexual interest among child molesters and normal heterosexual men. Behaviour Research and Therapy, 34, 389-394. doi:10.1016/0005-7967(95)00070-4 


\section{SUBTYPES OF CHILD SEXUAL ABUSERS}

Harris, G. T., Rice, M. E., Quinsey, V. L., Chaplin, T. C., \& Earls, C. (1992). Maximizing the discriminant validity of phallometric assessment data. Psychological Assessment, 4, 502-511. doi:10.1037//1040-3590.4.4.502

Helmus, L., Thornton, D., Hanson, R. K., \& Babchishin, K. M. (2012). Improving the predictive accuracy of Static-99 and Static-2002 with older sex offenders: Revised age weights. Sexual Abuse: $A$ Journal of Research and Treatment, 24, 64-101. doi: 10.1177/1079063211409951

Imhoff, R. \& Schmidt, A. F. (2013). Sexual disinhibition under sexual arousal: Evidence for domain specificity across gender. Manuscript submitted for publication.

Imhoff, R., Schmidt, A. F., Nordsiek, U., Luzar, C., Young, A. W. \& Banse, R. (2010). Viewing time effects revisited: Prolonged response latencies for sexually attractive targets under restricted task conditions. Archives of Sexual Behavior, 39, 1275-1288. doi:10.1007/s10508-009-9595-2

Imhoff, R., Schmidt, A. F., Weiß, S., Young, A. W., \& Banse, R. (2012). Vicarious Viewing Time: Prolonged response latencies for sexually attractive targets as a function of task- or stimulusspecific processing. Archives of Sexual Behavior, 41, 1389-1401. doi:10.1007/s10508-011$9879-1$

Kalmus, E., \& Beech, A. R. (2005). Forensic assessment of sexual interest: A review. Aggression and Violent Behavior, 10, 193-218. doi:10.1016/j.avb.2003.12.002

Laws, D. R. (2003). Penile plethysmography: Will we ever get it right? In T. Ward, D. R. Laws, \& S. M. Hudson (Eds.), Sexual deviance-Issues and controversies (pp. 82-102). London: Sage.

Letourneau, E. J. (2002). A comparison of objective measures of sexual arousal and interest: Visual reaction time and penile plethysmography. Sexual Abuse: A Journal of Research and Treatment, 14, 207-223. doi:10.1177/107906320201400302

Mann, R. E., Hanson, K. R., \& Thornton, D. (2010). Assessing risk for sexual recidivism: Some proposals on the nature of psychologically meaningful risk factors. Sexual Abuse: A Journal of Research and Treatment, 22, 191-217. doi:10.1177/1079063210366039 


\section{SUBTYPES OF CHILD SEXUAL ABUSERS}

Maruna, S., \& Mann, R. E. (2006). A fundamental attribution error? Rethinking cognitive distortions. Legal and Criminological Psychology, 11, 155-177. doi:10.1348/135532506X114608

Marshall, W. L. (2007). Diagnostic issues, multiple paraphilias, and comorbid disorders in sexual offenders: Their incidence and treatment. Aggression and Violent Behavior, 12, 16-35. doi:10.1016/j.avb.2006.03.001

Marshall, W. L., \& Fernandez, Y. L. (2000). Phallometric testing with sexual offenders: Limits to its value. Clinical Psychology Review, 20, 807-822. doi:10.1016/S0272-7358(99)00013-6

Mathie, N. L. \& Wakeling, C. (2011). Assessing socially desirable responding and its impact on selfreport measures among sexual offenders. Psychology, Crime \& Law, 17, 215-237. doi:10.1080/10683160903113681

Nunes, K. L., Firestone, P., \& Baldwin, M. W. (2007). Indirect assessment of cognitions of child sex abusers with the Implicit Association Test. Criminal Justice and Behavior, 34, 454-475. doi:10.1177/0093854806291703

Ó Ciardha, C. (2011). A theoretical framework for understanding deviant sexual interest and cognitive distortions as overlapping constructs contributing to sexual offending against children. Aggression and Violent Behavior, 16, 493-502. doi:10.1016/j.avb.2011.05.001

Pacific Psychological Assessment Cooperation (2004). The Not-Real People Stimulus Set for Assessment of sexual interest. Victoria, BC: Pacific Psychological Assessment Cooperation.

Quinsey, V. L. (1986). Men who have sex with children. In D. N. Weisstub (Ed.), Law and mental health: International perspectives (Vol. 2, pp. 140-172). New York, NY: Pergamon Press.

Rice, M. E., \& Harris, G. T. (2002). Men who molest their sexually immature daughters: Is a special explanation required? Journal of Abnormal Psychology, 111, 329-339. doi:10.1037//0021843X.111.2.329 


\section{SUBTYPES OF CHILD SEXUAL ABUSERS}

Schmidt, A. F., Banse, R., \& Imhoff, R. (in press). Indirect measures in forensic contexts. In F. J. R. van de Vijver, \& T. Ortner (Eds.), Behavior-based assessment: Going beyond self report in the personality, affective, motivation, and social domains. Göttingen: Hogrefe.

Schmidt, A. F., Mokros, A., \& Banse, R. (2012). Adult Men's Sexual Interest in Children: A Taxometric Analyis based on Direct and Indirect Measures. Manuscript submitted for publication.

Serin, R. C., Malcolm, P. B., Khanna, A., \& Barbaree, H. E. (1994). Psychopathy and deviant sexual arousal in incarcerated sexual offenders. Journal of Interpersonal Violence, 9, 3-11. doi:10.1177/088626094009001001

Seto, M. C. (2008). Pedophilia and sexual offending against children: Theory, assessment and intervention. Washington, DC: APA. doi:10.1037/11639-000

Seto, M. C., Cantor, J. M., \& Blanchard, R. (2006). Child pornography offenses are a valid diagnostic indicator of pedophilia. Journal of Abnormal Psychology, 115, 610-615. doi:10.1037/0021843X.115.3.610

Seto, M. C., Hanson, K. C., \& Babchishin, K. M. (2011). Contact sexual offending by men with online sexual offenses. Sexual Abuse: A Journal of Research and Treatment, 23, 124-145. doi:10.1177/1079063210369013

Seto, M. C., Harris, G. T., Rice, M. E., \& Barbaree, H. E. (2004). The Screening Scale for Pedophilic Interests and recidivism among adult sex offenders with child victims. Archives of Sexual Behavior, 33, 455-466. doi:10.1023/B:ASEB.0000037426.55935.9c

Seto, M. C., \& Lalumière, M. L. (2001). A brief screening scale to identify pedophilic interests among child molesters. Sexual Abuse: A Journal of Research and Treatment, 13, 15-25. doi:10.1177/107906320101300103

Seto, M. C., \& Lalumière, M. L., \& Kuban, M. (1999). The sexual preferences of incest offenders. Journal of Abnormal Psychology, 108, 267-272. doi:10.1037//0021-843X.108.2.267 


\section{SUBTYPES OF CHILD SEXUAL ABUSERS}

Snowden, R. J., Craig, R. L., \& Gray, N. S. (2011). Indirect behavioral measures of cognition among sexual offenders. Journal of Sex Research, 48, 192-217. doi:10.1080/00224499.2011.557750

Stinson, J. D., \& Becker, J. V. (2008). Assessing sexual deviance: A comparison of physiological, historical, and self-report measures. Journal of Psychiatric Practice, 14, 379-388. doi:10.1097/01.pra.0000341892.51124.85

Sullivan, C. (2007). Internet traders of child pornography: Profiling research-update. Auckland, New Zealand: Department of Internal Affairs. Retrieved November, 19, 2012, from http://www.dia.govt.nz/pubforms.nsf/URL/InternetTradersOfChildPornographyProfilingResearchUpdate-February2007.pdf/\$file/InternetTradersOfChildPornographyProfilingResearchUpdate-February2007.pdf

Tan, L. \& Grace, R. C. (2008). Social desirability and sexual offenders: A review. Sexual Abuse: A Journal of Research and Treatment, 20, 61-87. doi: 10.1177/1079063208314820

Tanner, J. (1978). Foetus into man: Physical growth from conception to maturity. Cambridge, MA: Harvard University Press.

Thornton, D., \& D. R. Laws (2009a). Cognitive approaches to the assessment of sexual interest in sexual offenders. Chichester, West Sussex: Wiley-Blackwell. doi:10.1002/9780470747551

Thornton, D., \& D. R. Laws (2009b). Postscript: Steps towards effective assessment of sexual interest. In D. Thornton, \& D. R. Laws (eds.), Cognitive approaches to the assessment of sexual interest in sexual offenders (pp. 225-227). Chichester, West Sussex: Wiley-Blackwell. doi:10.1002/9780470747551

Ward, T., \& Beech, T. (2006). An integrated theory of sexual offending. Aggression and Violent Behavior, 11, 44-63. doi:10.1016/j.avb.2005.05.002

Ward, T., Mann, R. E., \& Gannon, T. (2007). The good lives model of offender rehabilitation: Clinical implications. Aggression and Violent Behavior, 12, 87-107. doi:10.1016/j.avb.2006.03.004 


\section{SUBTYPES OF CHILD SEXUAL ABUSERS}

Ward, T., \& Siegert, R. J. (2002). Toward a comprehensive theory of child sexual abuse: A theory knitting perspective. Psychology, Crime and Law, 8, 319-351. doi:10.1080/10683160208401823

Ward, T., \& Stewart, C. (2003). Criminogenic needs and human needs. A theoretical model. Psychology, Crime \& Law, 9, 125-143. doi:10.1080/1068316031000116247

Winters, J., Kalina, C., \& Gorzalka, B. B. (2010). Dysregulated sexuality and high sexual drive: Distinct constructs? Archives of Sexual Behavior, 39, 1029-1043. doi:10.1007/s10508-009-9591-6

Wolak, J., Finkelhor, D., \& Kimberly, M. (2011). Child pornography possessors: Trends in offender and case characteristics. Sexual Abuse: A Journal of Research and Treatment, 23, 22-42.

doi:10.1177/1079063210372143 


\section{SUBTYPES OF CHILD SEXUAL ABUSERS}

Table 1. Overview of descriptive statistics and group differences

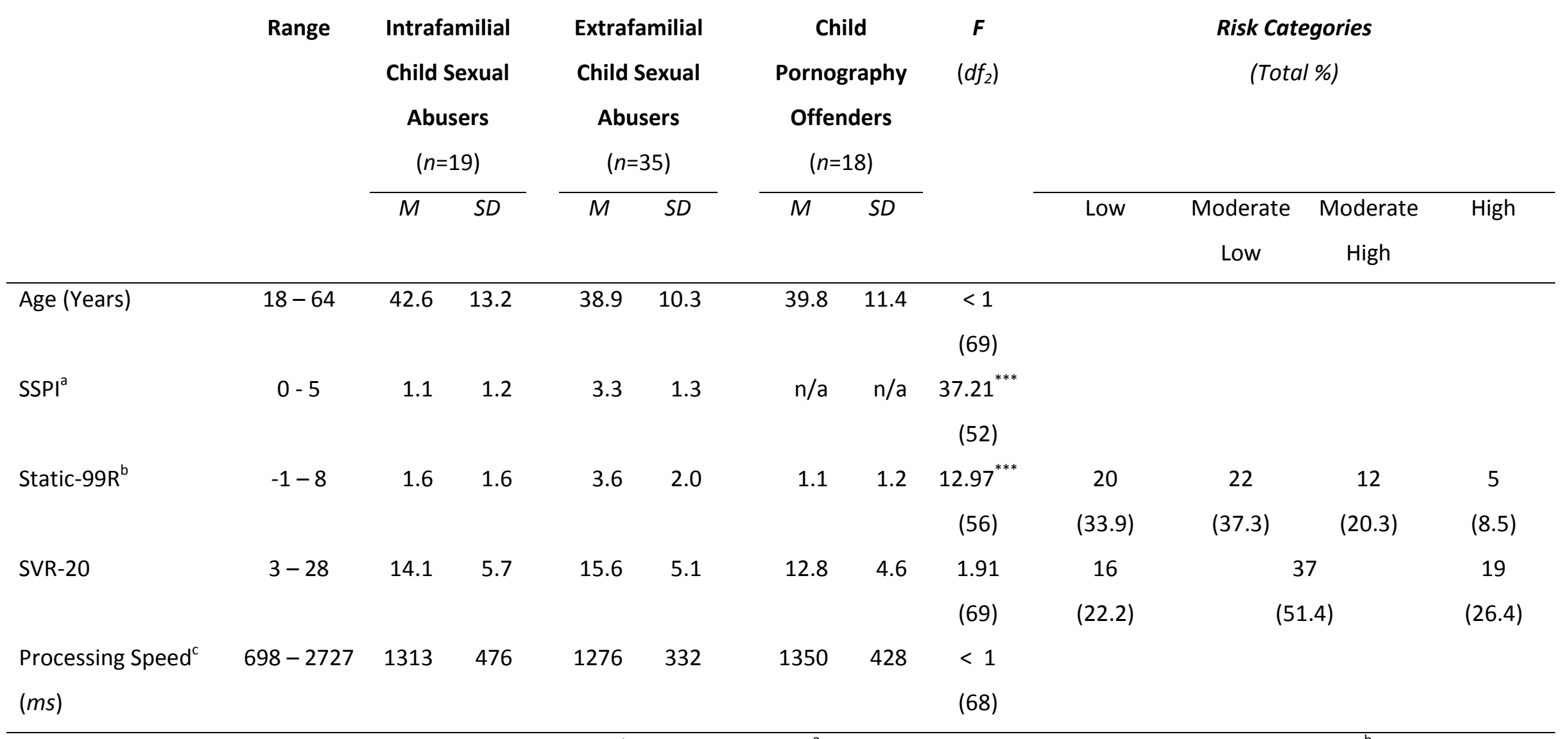

Note. $N=72 ; \mathrm{SSPI}=$ Screening Scale for Pedophilic Interest; $\mathrm{n} / \mathrm{a}=$ not applicable; ${ }^{\mathrm{a}} \mathrm{N}=53$ (score is only applicable to contact offenders); ${ }^{\mathrm{b}} \mathrm{N}=59$ (group sizes $n=13 / 31 / 15$ respectively); ${ }^{c} N=71$ ( $n=18$ intrafamilial abusers); ${ }^{* * *} p<.001$ 
Table 2. Reliability and construct validity of EISIP measures

\begin{tabular}{|c|c|c|c|c|c|c|c|c|c|c|c|}
\hline $\begin{array}{c}\text { Sex. Interests/ } \\
\text { Preferences }\end{array}$ & $\alpha$ & $\mathrm{Age}^{\mathrm{c}}$ & $\begin{array}{c}\text { Processing } \\
\text { Speed }\end{array}$ & SSPI $^{\mathrm{a}}$ & $\begin{array}{l}\text { Static-99R } \\
\text { Score }^{b}\end{array}$ & $\begin{array}{c}\text { SVR-20 } \\
\text { Score }\end{array}$ & $\begin{array}{c}\text { SVR-20 } \\
\text { Rating }\end{array}$ & $\begin{array}{l}\text { Child Porn } \\
\text { Offending }\end{array}$ & $\begin{array}{l}\text { Girls-Only } \\
\text { Offending }^{\mathrm{a}}\end{array}$ & $\begin{array}{c}\text { ESIQ } \\
\text { Fantasizing }\end{array}$ & $\begin{array}{l}\text { Antisociality } \\
\text { Index }\end{array}$ \\
\hline \multicolumn{12}{|c|}{ Self-report (ESIQ) } \\
\hline Women & .93 & .15 & -.03 & $-.43^{* * *}$ & $-.33^{*}$ & .01 & .02 & -.15 & $.55^{* * *}$ & $-.16^{d}$ & .14 \\
\hline Men & .96 & -.05 & .07 & $.57^{* * *}$ & $.48^{* * *}$ & -.05 & -.02 & -.18 & $-.69^{* * *}$ & $.35^{* * d}$ & -.07 \\
\hline Girls & .89 & -.21 & -.12 & $.33^{*}$ & .19 & -.02 & .09 & -.14 & -.16 & $.40^{* * *} \mathrm{~d}$ & -.03 \\
\hline Boys & .91 & -.11 & -.02 & $.48^{* * *}$ & $.41^{* *}$ & .08 & .08 & -.04 & $-.58^{* * *}$ & $.56^{* * * d}$ & -.12 \\
\hline Deviance Index & $\mathrm{n} / \mathrm{a}$ & -.20 & -.01 & $.45^{* *}$ & $.29^{*}$ & .06 & .08 & .12 & $-.43^{* *}$ & $.86^{* * *} \mathrm{e}$ & -.12 \\
\hline \multicolumn{12}{|l|}{ Viewing Time } \\
\hline Women & .90 & .14 & .17 & $-.28^{*}$ & $-.37^{* *}$ & .06 & .04 & .01 & $.37^{* *}$ & $-.24^{*}$ & $.29^{*}$ \\
\hline Men & .90 & .12 & $.26^{*}$ & $.35^{* *}$ & .13 & -.05 & -.17 & .10 & $-.47^{* * *}$ & -.06 & .03 \\
\hline Girls & .93 & .04 & .07 & .20 & -.13 & .04 & .09 & -.02 & .00 & $.32^{* *}$ & .21 \\
\hline Boys & .95 & -.02 & .17 & $.38^{* *}$ & .23 & -.04 & -.10 & .11 & $-.47^{* * *}$ & .18 & -.08 \\
\hline Deviance Index & $\mathrm{n} / \mathrm{a}$ & -.19 & -.07 & $.48^{* * *}$ & $.33^{* *}$ & -.04 & .00 & -.03 & $-.42^{* *}$ & $.52^{* * *}$ & -.17 \\
\hline \multicolumn{12}{|l|}{ IATs } \\
\hline Men-Women & .89 & -.17 & .20 & .20 & $.31^{*}$ & .09 & -.04 & .02 & -.21 & .03 & .10 \\
\hline Girls-Women & .82 & -.15 & .10 & $.38^{* *}$ & $.30^{*}$ & .06 & .03 & -.06 & -.23 & $.35^{* *}$ & .03 \\
\hline Boys-Men & .61 & .02 & .17 & .27 & $.27^{*}$ & .17 & .20 & -.06 & $-.29^{*}$ & $.29^{*}$ & .05 \\
\hline Deviance Index & $\mathrm{n} / \mathrm{a}$ & -.05 & .09 & $.33^{*}$ & $.29^{*}$ & .12 & .12 & -.08 & $-.32^{*}$ & $.36^{* *}$ & -.04 \\
\hline \multicolumn{12}{|c|}{ Aggregated EISIP Maximum Deviant Sexual Preferences } \\
\hline Deviance Index & $\mathrm{n} / \mathrm{a}$ & -.14 & .03 & $.53^{* * *}$ & $.39^{* *}$ & .06 & .07 & .02 & $-.49^{* * *}$ & $.54^{* * *}$ & -.14 \\
\hline
\end{tabular}


SUBTYPES OF CHILD SEXUAL ABUSERS

Table 3. Criterion validity of Sexual Fantasizing and Antisociality indexes as well as offending types

\begin{tabular}{|c|c|c|c|c|c|c|c|}
\hline & $\begin{array}{c}\text { Antisociality } \\
\text { Index }\end{array}$ & $\begin{array}{l}\text { Child Porn } \\
\text { Offending }\end{array}$ & $\begin{array}{l}\text { Girls-Only } \\
\text { Offending }^{a}\end{array}$ & SSPI $^{a}$ & $\begin{array}{c}\text { Static-99R } \\
\text { Score }^{b}\end{array}$ & $\begin{array}{l}\text { SVR-20 } \\
\text { Score }\end{array}$ & $\begin{array}{l}\text { SVR-20 } \\
\text { Rating }\end{array}$ \\
\hline ESIQ Fantasizing & -.10 & $-.25^{*}$ & $-.51^{*}$ & $.57^{* *}$ & $.41^{* *}$ & -.06 & .04 \\
\hline Antisociality Index & & $-.26^{*}$ & .21 & $-.28^{*}$ & .09 & $.51^{* * *}$ & $.49^{* * *}$ \\
\hline Child Pornography & & & $\mathrm{n} / \mathrm{a}$ & $\mathrm{n} / \mathrm{a}$ & $-.41^{* *}$ & -.19 & $-.31^{* *}$ \\
\hline \multicolumn{8}{|l|}{ Offending } \\
\hline Girls-Only & & & & $-.83^{* * *}$ & $-.47^{* *}$ & .07 & .06 \\
\hline Offending $^{a}$ & & & & & & & \\
\hline
\end{tabular}

Note. $N=72 ;{ }^{\mathrm{a}} N=54 ;{ }^{\mathrm{b}} N=59 ; \mathrm{n} / \mathrm{a}=$ not applicable

${ }^{* * *} p<.001 ;{ }^{* *} p<.01 ;{ }^{*} p<.05$ 
Table 4. Group differences on aggregated EISIP and Antisociality indexes

\begin{tabular}{|c|c|c|c|c|c|c|c|}
\hline & \multirow{2}{*}{\multicolumn{2}{|c|}{ Intrafamilial }} & & \multicolumn{2}{|c|}{ Child } & \multirow{5}{*}{$\begin{array}{c}\boldsymbol{F} \\
\left(d f_{2}\right)\end{array}$} \\
\hline & & & Child S & iual & Pornc & aphy & \\
\hline & \multirow{2}{*}{\multicolumn{2}{|c|}{$\begin{array}{l}\text { Abusers } \\
(n=19)\end{array}$}} & \multirow{2}{*}{\multicolumn{2}{|c|}{$\begin{array}{l}\text { Abusers } \\
(n=35)\end{array}$}} & \multirow{2}{*}{\multicolumn{2}{|c|}{$\begin{array}{l}\text { Offenders } \\
\qquad(n=18)\end{array}$}} & \\
\hline & & & & & & & \\
\hline & $M$ & $S D$ & $M$ & $S D$ & $M$ & $S D$ & \\
\hline EISIP & $-0.35_{A}$ & 0.36 & $0.19_{B}$ & 0.83 & $0.04_{A B}$ & 0.90 & $6.12^{* *}$ \\
\hline Deviance Index ${ }^{\#}$ & & & & & & & (37.49) \\
\hline Antisociality & $0.71_{\mathrm{A}}$ & 0.54 & $0.43_{A B}$ & 0.40 & $0.27_{B}$ & 0.31 & $4.79^{*}$ \\
\hline Index ${ }^{\tilde{2}}$ & & & & & & & (37.74) \\
\hline ESIQ & $0.25_{\mathrm{AB}}$ & 0.11 & $0.33_{\mathrm{A}}$ & 0.15 & $0.23_{B}$ & 0.12 & $4.74^{*}$ \\
\hline Fantasizing ${ }^{\sim}$ & & & & & & & (41.28) \\
\hline ESIQ Fantasies & $-0.84_{A}$ & 0.18 & $-0.61_{A B}$ & 0.47 & $-0.46_{B}$ & 0.70 & $5.35^{* *}$ \\
\hline Children-Adults ${ }^{\sim}$ & & & & & & & (35.41) \\
\hline
\end{tabular}

Note. $N=72$; group means with different subscripts in one row are statistically different

(Tukey-HSD post-hoc comparisons, $p<.05) ;{ }^{\#} z$-values; Welch-Test (Dunnett's $C$ post-hoc comparisons, $p<.05) ;{ }^{*} p<.05 ;{ }^{* *} p<.01$ 
SUBTYPES OF CHILD SEXUAL ABUSERS

\section{Figures}

Figure 1. Overview of self-reported sexual fantasies (error bars $\pm 1 S E$ ). 
Figure 1

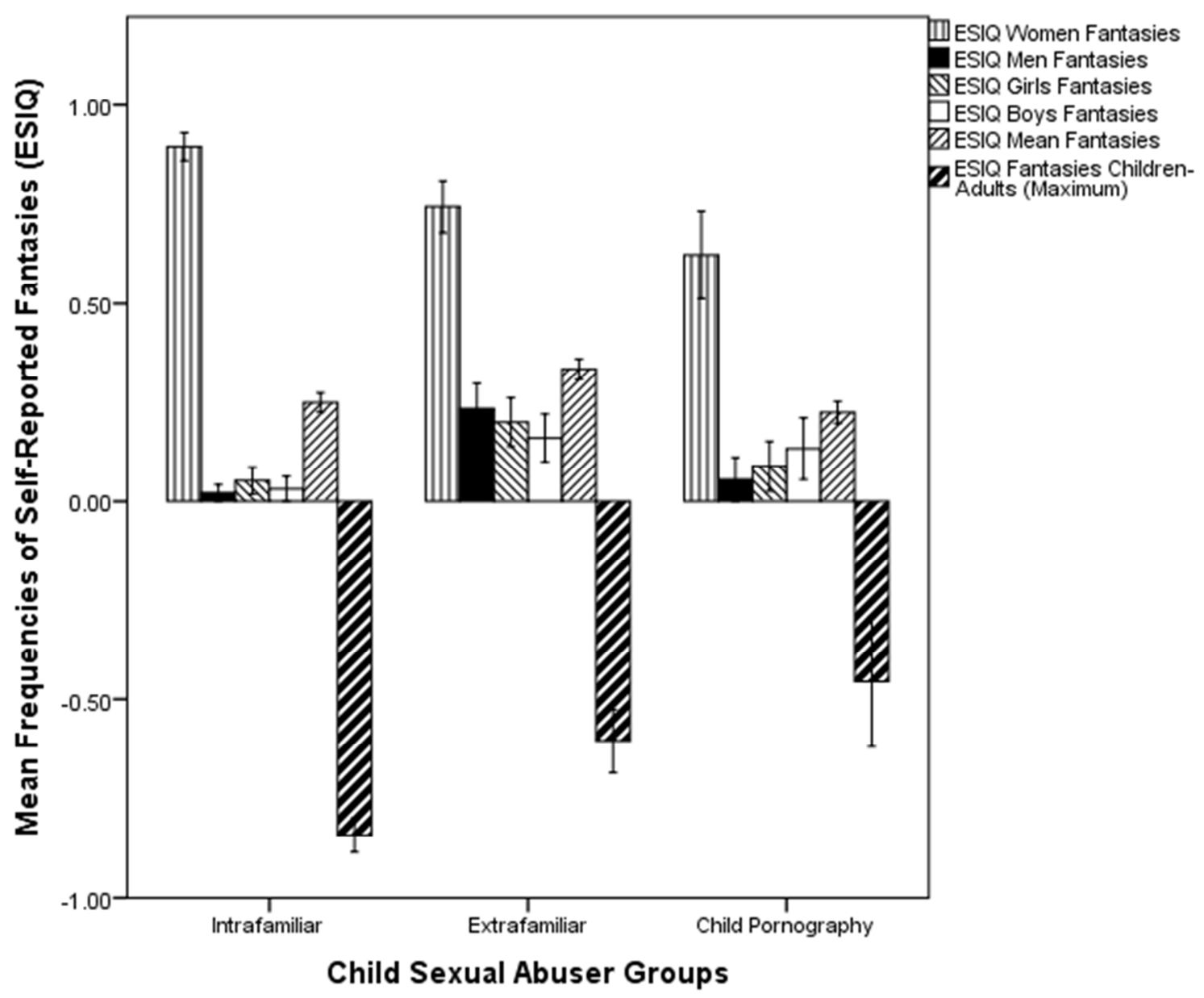

